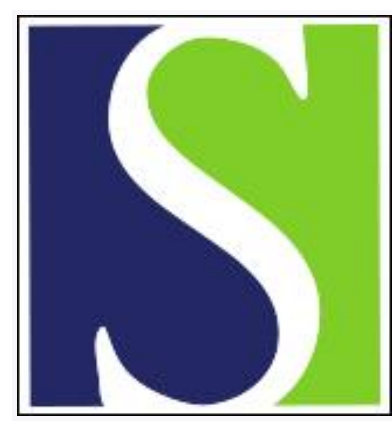

Scand J Work Environ Health 1990;16(6):434-439

https://doi.org/10.5271/sjweh.1763

Issue date: 01 Dec 1990

Dust in buildings with man-made mineral fiber ceiling boards. by Schneider T, Nielsen $O$, Bredsdorff $P$, Linde $P$

Affiliation: National Institute of Occupational Health, Copenhagen, Denmark.

This article in PubMed: www.ncbi.nlm.nih.gov/pubmed/2284592 


\title{
Dust in buildings with man-made mineral fiber ceiling boards
}

\author{
by Thomas Schneider, MSc, ${ }^{1}$ Ove Nielsen, MSc, ${ }^{2}$ Per Bredsdorff, MSc, ${ }^{3}$ Peter Linde, $\mathrm{MSc}^{4}$
}

\begin{abstract}
SCHNEIDER T, NIELSEN O, BREDSDORFF P, LINDE P. Dust in buildings with man-made mineral fiber ceiling boards. Scand J Work Environ Health 1990;16:434-9. Man-made mineral fibers (MMMF) and other airborne dusts were measured in 105 rooms in a representative sample of public buildings, excluding rooms with physically damaged boards or buildings with notable indoor climate problems. There were no differences in the MMMF concentrations with respect to the type of binder. The average concentrations ranged from 17 to 210 respirable $\mathrm{MMMF} / \mathrm{m}^{3}$. The average concentrations of the reference group was intermediate and therefore indicated that sources other than ceiling boards contributed to the obtained values. No grouping by concentration of MMMF on cupboards was possible. Airborne concentrations of respirable MMMF were 2.7 times lower in rooms with mechanical ventilation than in rooms with natural ventilation. For nonrespirable MMMF, the most important factor was the quality of the cleaning. The concentration in poorly cleaned rooms was 5.5 times that of well-cleaned rooms. Ventilation, quality of cleaning, and number of persons affected the non-MMMF and total dust concentrations.
\end{abstract}

Key terms: cleaning, indoor air, surface, ventilation.

During the last decade, there have been several reports on man-made mineral fibers (MMMF) in the indoor environment and their occurrence and role in the sick building syndrome. A recent review which deals with occurrence and health effects in general can be found in reference 1. Several studies have been made in Denmark. One such study (2) reported concentrations ranging from nondetectable to 240 respirable MMMF $/ \mathrm{m}^{3}$ in schools with mechanical ventilation and very high episodic concentrations, above 1000 respirable and 100 nonrespirable $\mathrm{MMMF} / \mathrm{m}^{3}$, in buildings with reported complaints about the indoor air. Rindel et al (3), reporting on a study in Danish kindergartens, concluded that the measured pollution levels (average less than $200 \mathrm{MMMF} / \mathrm{m}^{3}$ ) originating from readily visible ceiling boards hardly explained the reported symptoms and diseases. Skov \& Valbjorn (4) found only airborne MMMF in one out of 14 Danish town halls (analytical sensitivity 70 fibers $/ \mathrm{m}^{3}$ ). A specially developed laboratory test and a full-scale test (5) showed that fiber release from modern boards with water-resistant binders was unmeasurably low. It was recommended that MMMF boards should be vacuumed after they are cut to the proper size at the construction site.

The obvious source of fibers in buildings was believed to be the MMMF ceiling boards. Non-MMMF

1 National Institute of Occupational Health, Copenhagen, Denmark.

2 National Building Agency, Danish Ministry of Housing and Building, Copenhagen, Denmark.

3 Danish Building Research Institute (retired), Horsholm, Denmark.

4 National Danish Institute of Social Research, Copenhagen, Denmark.

Reprint requests to: Mr T Schneider, National Institute of Occupational Health, Lersø Parkalle 105, DK-2900 Copenhagen, Denmark. fibers were known to be present in concentrations that were much higher than those of MMMF (2). There were also indications that MMMF on surfaces may be responsible for some cases of skin itching and irritation of the upper airways and eyes (2). Therefore we decided to measure the MMMF concentrations in air and on surfaces, non-MMMF fibers in air, and total dust in air in a random sample of Danish buildings with MMMF ceiling boards. Preliminary results of this study have been presented (6), and the results have been quoted in reference 1 . This paper presents results from the final report (7) with additional data and analyses.

\section{Materials and methods}

A sample of rooms with MMMF ceiling boards of types covering the Danish market and building habits was selected from nurseries, kindergartens, schools, and offices listed by the municipalities in and around Greater Copenhagen. Rooms having physically damaged boards or notable indoor climate problems were excluded. As a result, nine different types of MMMF ceiling board and one type without MMMF (reference group) were included in the study (table 1). The following building/room-related background variables were used: (i) type of room, (ii) number of persons in the room during the measurement, (iii) quality of cleaning subjectively ranked as good, medium, and poor with the number of weekly cleaning hours relative to the building area as the main criteria, (iv) floor number, (v) air temperature, (vi) air humidity.

No changes in the usual activities were introduced. There was no information on smoking, but smoking would not have occurred in nurseries, kindergartens, and schools. 
Airborne dust was sampled at three stationary sites in each room, $1.1 \mathrm{~m}$ above the floor. Two of the sites were for fibers and one was for total dust.

The sampling duration was typically $1-2 \mathrm{~h}$, and 37-mm filter cassettes were used. Fibers were sampled on $1.2 \mu \mathrm{m}$ cellulose acetate filters in open cassettes with a protective aluminum cowl, facing upward, and a face velocity of $0.04 \mathrm{~m} / \mathrm{s}$. Total dust was sampled on 3- $\mu \mathrm{m}$ Fluoropore ${ }^{\circledR}$ (Millipore) filters in closed-face cassettes with an entry velocity of $1.25 \mathrm{~m} / \mathrm{s}$.

The total dust filters were weighed on a microbalance in a room at a constant temperature and relative humidity $(50 \pm 3 \%)$, with a precision of $20 \mu \mathrm{g}$. MMMF and other fibers were analyzed with standard positive phase contrast microscopy under an objective with a magnification of $40 \times$. A polarizer and an analyzer were added to test for birefringence as described in reference 2 . The composition of the nonMMMF was not determined, but their visual appearance led us to believe that the majority were organic. The analytical sensitivity (ie, concentration corresponding to one fiber detected) was $70 \mathrm{MMMF} / \mathrm{m}^{3}$ and 230 non-MMMF $/ \mathrm{m}^{3}$. The same criterion for respirability (diameter less than $3 \mu \mathrm{m}$ ) was used for nonMMMF. The counts were corrected for blank values: 0 for MMMF and $3 / \mathrm{mm}^{2}$ for non-MMMF. Earlier measurements had shown that the number of respirable non-MMMF in the $5-10 \mu \mathrm{m}$ length range [L(5-10)] was strongly correlated with the number of respirable non-MMMF in the range longer than 10 $\mu \mathrm{m}[\mathrm{L}(10-\infty)]$. Only $\mathrm{L}(10-\infty)$ were counted. The conversion $\mathrm{L}(5-\infty)=1.76 \cdot \mathrm{L}(10-\infty)$ can be used for comparing the data with earlier results given as $\mathrm{L}(5-\infty)$.

Dust settled on horizontal nontextile surfaces was sampled with sticky gelatinous foils (2). The sampling sites were stratified. A table was considered to represent surfaces regularly cleaned and the top of a cupboard to represent surfaces not regularly cleaned. No attempt was made to determine the elapsed time since the last cleaning of the surface. The measurements thus reflect the state of contamination of the surface at the time of the sampling.

Settled MMMF were analyzed under a microscope with a transmitted light objective (magnification $20 \times$ ) with a polarizer and an analyzer and with projection onto a digitizer for size determination. About $70 \%$ of all the fibers detectable in a $40 \times$ phase contrast microscope were seen with this method. All fibers longer than $50 \mu \mathrm{m}$ or thicker than $3 \mu \mathrm{m}$ were detected. This method is thus suitable for settled fibers, since the majority are larger than these sizes (table 10). The analytical sensitivity was 0.6 fibers $/ \mathrm{cm}^{2}$. Blank foils gave no MMMF counts.

The distributions of the airborne fiber concentrations were very skew and with a large number of 0 fibers counted. On the average, 54 (range $0-84$ ) $\%$ of all the samples in the groups defined by ceiling type had no detected fibers. The summary statistics were thus based on simple arithmetic averages. The result for each room was obtained as an average of the two parallel samples. Since the concentrations were the results of fiber counts and thus, ideally, would be Poisson-distributed, the data were transformed by square root as this procedure renders a Poisson distribution that is approximately normal. The transformed distribution was still skew, however. Average values of the data transformed by square root for the ceiling types were grouped homogeneously with Duncan's method of multiple comparisons of means (8). A homogeneous group was a group with no significant differences between the means of the members of the group.

The square-root data on airborne fiber concentration were analyzed and related to the background variables with a multidimensional analysis of variance of the SAS (statistical analysis system) (9). First, all nine variables were included. Then the least significant was omitted and the procedure was repeated until only variables having a level of significance of at most $5 \%$ were left.

We decided to concentrate the statistical analysis of the MMMF on surfaces to total MMMF $/ \mathrm{cm}^{2}$ on cupboards. It was assumed that these surfaces would reflect possible differences between ceiling types better than the table surfaces. The square-root data on the total $\mathrm{MMMF} / \mathrm{cm}^{2}$ on cupboards were subjected to a two-dimensional analysis of variance. The first dimension was ceiling types (on 10 levels), and the second dimension was the quality of cleaning (on two levels) (table 5).

\section{Results}

The results for the airborne MMMF concentrations averaged for each ceiling type are shown in table 1 . The standard deviations in table 1 are measures of the total variation, which consisted of two independent sources, namely, the variation between two parallel samples and the variation between averages for rooms. The standard deviation due to parallel samples was proportional to the average concentration and was of the order of $100 \%$. This large value can be explained by the low fiber concentrations in comparison with the analytical sensitivity.

For both respirable and nonrespirable airborne MMMF, the ceiling boards could be subdivided into three homogeneous groups. Table 2 shows the grouping according to respirable fibers. In the same table, the concentration and the groups corresponding to nonrespirable fibers are shown.

For the respirable fibers that were airborne, the only significant background variables were type of ceiling and ventilation. For the airborne nonrespirable fibers the only significant background variables were type of ceiling and quality of cleaning. Since ventilation had an effect on the concentration of respirable fibers and since, in the various groups in table 2 , there was a vari- 
Table 1. Airborne concentrations of man-made mineral fibers (MMMF) by type of ceiling board.

\begin{tabular}{|c|c|c|c|c|c|c|c|c|}
\hline \multirow{3}{*}{ Type of ceiling board } & \multirow{3}{*}{$\begin{array}{l}\text { Water- } \\
\text { soluble } \\
\text { binder }\end{array}$} & \multirow{3}{*}{$\begin{array}{c}\text { Number } \\
\text { of } \\
\text { rooms }\end{array}$} & \multicolumn{6}{|c|}{$M M M F / m^{3}$} \\
\hline & & & \multicolumn{3}{|c|}{ Respirable } & \multicolumn{3}{|c|}{ Nonrespirable } \\
\hline & & & Mean & $S D^{a}$ & Range & Mean & $S D^{a}$ & Range \\
\hline $\begin{array}{l}\text { Karlit Mineral }{ }^{\mathrm{b}} \text { (German basalt, } \\
\text { hard, untreated, direct mount) }\end{array}$ & Yes & 11 & 213 & 414 & $0-1660$ & 57 & 96 & $0-330$ \\
\hline $\begin{array}{l}\text { Hotaco Mineral }{ }^{b} \text { (German basalt, hard, } \\
\text { lightly varnished, direct mount) }\end{array}$ & Yes & 14 & 56 & 113 & $0-430$ & 21 & 50 & $0-190$ \\
\hline $\begin{array}{l}\text { Ny Hotaco Mineral }{ }^{b} \text { (Swiss basalt and } \\
\text { more binder, new product) }\end{array}$ & Yes & 2 & 95 & 35 & $60-130$ & 0 & $(\cdot)$ & $0-0$ \\
\hline Other with water-soluble binder & Yes & 12 & 59 & 89 & $0-360$ & 14 & 25 & $0-70$ \\
\hline $\begin{array}{l}\text { Soft mineral wool sealed on lower side, } \\
\text { suspended ceiling, visible profile }\end{array}$ & No & 13 & 26 & 75 & $0-340$ & 8 & 24 & $0-100$ \\
\hline $\begin{array}{l}\text { Hard mineral wool sealed on lower side, } \\
\text { suspended ceiling, hidden profile }\end{array}$ & No & 9 & 31 & 41 & $0-130$ & 10 & 23 & $0-70$ \\
\hline $\begin{array}{l}\text { Unsealed mineral, suspended ceiling, } \\
\text { visible profile or direct mount }\end{array}$ & No & 12 & 180 & 277 & $0-1030$ & 67 & 129 & $0-400$ \\
\hline Sealed on all six surfaces & No & 9 & 94 & 186 & $0-610$ & 46 & 79 & $0-240$ \\
\hline Batts on top of perforated panels & No & 11 & 17 & 30 & $0-100$ & 9 & 22 & $0-60$ \\
\hline No MMMF (reference group) & $\cdot$ & 12 & 62 & 128 & $0-620$ & 18 & 41 & $0-130$ \\
\hline Average & . & 105 & 82 & 195 & . & 27 & 67 & . \\
\hline
\end{tabular}

a Total variation

b Danish product names.

Table 2. Ceiling board types divided into three concentration groups (low, medium, and high). There is a nonsignificant difference between the means of the airborne concentration of man-made mineral fibers (MMMF) within the groups.

\begin{tabular}{|c|c|c|c|c|c|}
\hline \multirow{3}{*}{$\begin{array}{l}\text { Water- } \\
\text { soluble } \\
\text { binder }\end{array}$} & \multirow{3}{*}{ Type of ceiling board } & \multicolumn{4}{|c|}{$M M M F / m^{3}$} \\
\hline & & \multicolumn{2}{|c|}{ Respirable } & \multicolumn{2}{|c|}{ Nonrespirable } \\
\hline & & Mean & Group & Mean & Group \\
\hline $\begin{array}{l}\text { No } \\
\text { No }\end{array}$ & $\begin{array}{l}\text { Batts on top of perforated panels } \\
\text { Soft mineral wool }\end{array}$ & $\begin{array}{l}17 \\
26\end{array}$ & $\begin{array}{l}\text { Low } \\
\text { Low }\end{array}$ & $\begin{array}{l}9 \\
8\end{array}$ & $\begin{array}{l}\text { Medium } \\
\text { Medium }\end{array}$ \\
\hline $\begin{array}{l}\text { No } \\
\text { Yes } \\
\text { Yes } \\
\text { No }\end{array}$ & $\begin{array}{l}\text { Hard mineral wool } \\
\text { Hotaco Mineral } \\
\text { Other } \\
\text { No MMMF (reference group) } \\
\text { Sealed on all six surfaces }\end{array}$ & $\begin{array}{l}31 \\
56 \\
59 \\
62 \\
94\end{array}$ & $\begin{array}{l}\text { Medium } \\
\text { Medium } \\
\text { Medium } \\
\text { Medium } \\
\text { Medium }\end{array}$ & $\begin{array}{l}10 \\
21 \\
14 \\
18 \\
46\end{array}$ & $\begin{array}{l}\text { Medium } \\
\text { Medium } \\
\text { Medium } \\
\text { Medium } \\
\text { Medium }\end{array}$ \\
\hline $\begin{array}{l}\text { Yes } \\
\text { No } \\
\text { Yes }\end{array}$ & $\begin{array}{l}\text { New Hotaco Mineral } \\
\text { Unsealed mineral wool } \\
\text { Karlit Mineral }\end{array}$ & $\begin{array}{r}95 \\
180 \\
213\end{array}$ & $\begin{array}{l}\text { High } \\
\text { High } \\
\text { High }\end{array}$ & $\begin{array}{r}0 \\
67 \\
57\end{array}$ & $\begin{array}{l}\text { Low } \\
\text { High } \\
\text { High }\end{array}$ \\
\hline
\end{tabular}

Table 3. Ability of air and surface samples to reveal the presence of man-made mineral fibers (MMMF).

\begin{tabular}{lcccccc}
\hline & $\begin{array}{c}\text { Total } \\
\text { number } \\
\text { of rooms }\end{array}$ & $\begin{array}{c}\text { Rooms without MMMF } \\
\text { detected in air }\end{array}$ & & $\begin{array}{c}\text { Rooms without MMMF } \\
\text { detected on cupboards }\end{array}$ \\
\cline { 2 - 6 } & 95 & $\begin{array}{c}\text { Total } \\
\text { number }\end{array}$ & $\begin{array}{c}\text { Number with- } \\
\text { out MMMF } \\
\text { detected on } \\
\text { cupboards }\end{array}$ & & $\begin{array}{c}\text { Total } \\
\text { number }\end{array}$ & $\begin{array}{c}\text { Number with- } \\
\text { out MMMF } \\
\text { detected } \\
\text { in air }\end{array}$ \\
\cline { 2 - 6 } $\begin{array}{l}\text { Respirable fibers } \\
\text { Nonrespirable fibers }\end{array}$ & 95 & 34 & 5 & 12 & 5 \\
\hline
\end{tabular}

able proportion of buildings with different types of ventilation, we checked whether these factors would affect the grouping. It was found that correction for the ventilation effect would have strengthened the difference between the three groups.
As shown in table 3, there were 65 rooms in which no airborne nonrespirable MMMF were counted among the 95 rooms measured, but in most of these rooms nonrespirable MMMF were found on cupboards. In only eight of the rooms were no fibers 
Table 4. Total man-made mineral fiber (MMMF) concentration $/ \mathrm{cm}^{2}$ on the two types of surfaces.

\begin{tabular}{|c|c|c|c|c|c|c|c|c|}
\hline \multirow{3}{*}{$\begin{array}{l}\text { Type of ceiling } \\
\text { board }\end{array}$} & \multicolumn{8}{|c|}{ Total MMMF/cm ${ }^{2}$} \\
\hline & \multicolumn{4}{|c|}{ On table surfaces } & \multicolumn{4}{|c|}{ On cupboard surfaces } \\
\hline & $\begin{array}{l}\text { Number } \\
\text { of rooms }\end{array}$ & Mean & $S^{a}$ & Range & $\begin{array}{l}\text { Number } \\
\text { of rooms }\end{array}$ & Mean & $S D^{a}$ & Range \\
\hline Karlit Mineral ${ }^{b}$ & 11 & 0.25 & 0.28 & $0-0.99$ & 11 & 20 & 35 & $0-114$ \\
\hline Hotaco Mineral ${ }^{b}$ & 11 & 0.97 & 2.3 & $0-7.7$ & 18 & 19 & 23 & $0-81$ \\
\hline Ny Hotaco Min. ${ }^{b}$ & $\cdots$ & $\cdots$ & $\cdots$ & . & 1 & 18 & $\cdot$ & $\cdot$ \\
\hline $\begin{array}{l}\text { Other with water } \\
\text { soluble binder }\end{array}$ & 8 & 1.6 & 2.9 & $0-8.6$ & 10 & 35 & 48 & $0.28-154$ \\
\hline Soft wool & 6 & 0.46 & 0.76 & $0-2.0$ & 6 & 5.0 & 4.6 & $0-14$ \\
\hline Hard wool & 7 & 0.02 & 0.06 & $0-0.16$ & 9 & 11 & 12 & $0-33$ \\
\hline Unsealed & 9 & 1.3 & 1.25 & $0-3.3$ & 11 & 31 & 42 & $0-140$ \\
\hline Sealed & 6 & 9.7 & 23 & $0-57$ & 8 & 43 & 68 & $0.16-179$ \\
\hline $\begin{array}{l}\text { Batts on top } \\
\text { perforated panels }\end{array}$ & 9 & 0.14 & 0.17 & $0-0.49$ & 10 & 24 & 47 & $0.66-148$ \\
\hline No MMMF & 10 & 0.18 & 0.25 & $0-0.82$ & 12 & 43 & 70 & $0-200$ \\
\hline All & 77 & 1.33 & 6.6 & . & 96 & 25 & 43 & . \\
\hline
\end{tabular}

a Total variation.

b Danish product name.

Table 5. Total man-made mineral fiber (MMMF) concentration $/ \mathrm{cm}^{2}$ on the cupboards according to the quality of the cleaning.

\begin{tabular}{lcccc}
\hline \multirow{2}{*}{$\begin{array}{l}\text { Quality of } \\
\text { the cleaning }\end{array}$} & \multirow{2}{*}{$\begin{array}{c}\text { Number } \\
\text { of rooms }\end{array}$} & \multicolumn{3}{c}{ Total MMMF/cm } \\
\cline { 3 - 5 } & & Mean & SD & Range \\
\hline Poor & 33 & 50.9 & 59.8 & $0-154$ \\
Medium & 41 & 19.4 & 39.0 & $0-200$ \\
Good & 18 & 26.4 & 42.8 & $0-123$ \\
\hline Good + medium & 59 & 21.5 & 40.3 & $0-200$ \\
\hline
\end{tabular}

counted. On the whole, there were 10 rooms in which no nonrespirable MMMF were counted on the cupboards. In eight of these 10 rooms no airborne nonrespirable MMMF were counted either. It can thus be concluded that measurement of the surface concentration has a greater ability to detect the presence of fibers than measurement of the air concentration.

Table 4 shows the surface concentration of total MMMF for the tables and the cupboards.

Table 5 shows the surface concentration of total MMMF according to the quality of the cleaning. Since the mean for medium quality was a little less than the mean for high quality, these data were pooled.

The two-dimensional analysis of variance for total MMMF on cupboards showed that type of ceiling could not be shown to be a significant factor in explaining the variation in the data, whereas quality of cleaning was significant at a $3 \%$ level.

No significant subdivision of the averages over ceiling types into homogenous groups was found by Duncan's method, even if the level of significance was raised from 5 to $10 \%$.
Concentrations are given according to the type of building in table 6 for non-MMMF and for total dust. It should be noted that both contaminants ranked the building types in the same way.

The number of persons present influenced the MMMF, non-MMMF, and total dust concentrations as shown in table 7.

Type of ventilation and quality of cleaning influenced the airborne concentrations as shown in tables 8 and 9.

\section{Discussion}

A t-test on the data transformed by square-root showed that there was no significant difference in airborne MMMF between the two binder types, neither for respirable $(\mathrm{P}=0.19)$ nor for nonrespirable $(\mathrm{P}=0.78)$ airborne MMMF. As has already been stated, only rooms with undamaged ceilings were included.

Ceiling boards with no surface treatment and ceiling boards of an old type with water-soluble binder (taken out of production several years ago) were both placed in the high concentration group with regard to respirable and nonrespirable airborne MMMF concentrations. The reference group was placed in the medium group for both respirable and nonrespirable airborne MMMF. Therefore there were evidently other MMMF sources than ceilings. Infiltration from outdoor air could not be evaluated since no outdoor measurements were made, but it is unlikely that infiltration would contribute with nonrespirable fibers. Actually, all rooms without MMMF ceiling boards were on the top floor or in one-floor houses and thus in close proximity with the massive amount of MMMF present in 
Table 6. Airborne nonman-made mineral fiber (non-MMMF) and total dust concentrations.

\begin{tabular}{|c|c|c|c|c|c|c|c|c|c|c|c|}
\hline \multirow{3}{*}{$\begin{array}{l}\text { Building } \\
\text { type }\end{array}$} & \multicolumn{7}{|c|}{ Non-MMMF/m³ } & \multirow{2}{*}{\multicolumn{4}{|c|}{ Total dust (mg/m $\left.{ }^{3}\right)$}} \\
\hline & \multirow{2}{*}{$\begin{array}{l}\text { Number } \\
\text { of } \\
\text { measure- } \\
\text { ments }\end{array}$} & \multicolumn{3}{|c|}{ Respirable } & \multicolumn{3}{|c|}{ Nonrespirable } & & & & \\
\hline & & Mean & SD & Range & Mean & SD & Range & $\begin{array}{l}\text { Number } \\
\text { of } \\
\text { measure- } \\
\text { ments }\end{array}$ & Mean & SD & Range \\
\hline $\begin{array}{l}\text { Kindergartens } \\
\text { Nurseries } \\
\text { Schools } \\
\text { Miscellaneous } \\
\text { Offices }\end{array}$ & $\begin{array}{r}86 \\
8 \\
25 \\
12 \\
72\end{array}$ & $\begin{array}{r}210000 \\
157000 \\
63000 \\
26000 \\
20000\end{array}$ & $\begin{array}{r}186000 \\
107000 \\
65000 \\
20000 \\
14000\end{array}$ & $\begin{array}{c}23000-907000 \\
41000-327000 \\
3000-260000 \\
2000-65000 \\
0-64000\end{array}$ & $\begin{array}{r}54000 \\
40000 \\
21000 \\
15000 \\
7000\end{array}$ & $\begin{array}{r}60000 \\
20000 \\
18000 \\
24000 \\
5000\end{array}$ & $\begin{array}{c}3000-299000 \\
5000-89000 \\
2000-70000 \\
0-86000 \\
1000-25000\end{array}$ & $\begin{array}{r}42 \\
4 \\
11 \\
6 \\
32\end{array}$ & $\begin{array}{l}0.29 \\
0.27 \\
0.20 \\
0.16 \\
0.13\end{array}$ & $\begin{array}{l}0.16 \\
0.14 \\
0.13 \\
0.22 \\
0.09\end{array}$ & $\begin{array}{r}0.01-0.67 \\
0.12-0.44 \\
0-0.42 \\
0-0.57 \\
0.01-0.44\end{array}$ \\
\hline
\end{tabular}

Table 7. Influence of number of room occupants on dust level.

\begin{tabular}{|c|c|c|c|c|c|}
\hline \multirow{2}{*}{$\begin{array}{l}\text { Number of } \\
\text { occupants }\end{array}$} & \multicolumn{2}{|c|}{$\mathrm{MMMF} / \mathrm{m}^{3}$} & \multicolumn{2}{|c|}{ Non-MMMF/m ${ }^{3}$} & \multirow{2}{*}{$\begin{array}{c}\text { Total } \\
\text { dust } \\
\mathrm{mg} / \mathrm{m}^{3}\end{array}$} \\
\hline & Respirable & Nonrespirable & Respirable & Nonrespirable & \\
\hline $\begin{array}{l}\text { None } \\
1-4 \\
5-10 \\
>10\end{array}$ & $\begin{array}{r}36 \\
39 \\
80 \\
133\end{array}$ & $\begin{array}{l}17 \\
16 \\
25 \\
40\end{array}$ & $\begin{array}{r}97000 \\
23000 \\
105000 \\
184000\end{array}$ & $\begin{array}{r}17000 \\
8000 \\
33000 \\
49000\end{array}$ & $\begin{array}{l}0.11 \\
0.15 \\
0.22 \\
0.31\end{array}$ \\
\hline
\end{tabular}

Table 8. Effect of type of ventilation on airborne dust level.

\begin{tabular}{|c|c|c|c|c|c|}
\hline \multirow{2}{*}{ Ventilation } & \multicolumn{2}{|c|}{$\mathrm{MMMF} / \mathrm{m}^{3}$} & \multicolumn{2}{|c|}{ Non-MMMF/m³ } & \multirow{2}{*}{$\begin{array}{c}\text { Total } \\
\text { dust } \\
\mathrm{mg} / \mathrm{m}^{3}\end{array}$} \\
\hline & Respirable & Nonrespirable & Respirable & Nonrespirable & \\
\hline Natural & 107 & 36 & 144000 & 39000 & 0.26 \\
\hline Mechanical exhaust & 33 & 13 & 63000 & 16000 & 0.15 \\
\hline Mechanical exhaust + supply & 41 & 11 & 46000 & 14000 & 0.13 \\
\hline
\end{tabular}

Table 9. Effect of quality of cleaning on airborne dust level.

\begin{tabular}{|c|c|c|c|c|c|c|c|}
\hline \multirow{3}{*}{$\begin{array}{l}\text { Quality of } \\
\text { cleaning }\end{array}$} & \multirow{2}{*}{\multicolumn{2}{|c|}{$\frac{M M M F / m^{3}}{\text { Airborne }}$}} & \multirow{2}{*}{\multicolumn{2}{|c|}{$\frac{\mathrm{MMMF} / \mathrm{cm}^{2}}{\text { On cupboards }}$}} & \multirow{2}{*}{\multicolumn{2}{|c|}{ Non-MMMF/m ${ }^{3}$}} & \multirow{3}{*}{$\begin{array}{c}\text { Total } \\
\text { dust } \\
\left(\mathrm{mg} / \mathrm{m}^{3}\right)\end{array}$} \\
\hline & & & & & & & \\
\hline & $\begin{array}{l}\text { Respi- } \\
\text { rable }\end{array}$ & $\begin{array}{l}\text { Nonrespi- } \\
\text { rable }\end{array}$ & $\begin{array}{l}\text { Respi- } \\
\text { rable }\end{array}$ & $\begin{array}{c}\text { Nonrespi- } \\
\text { rable }\end{array}$ & $\begin{array}{l}\text { Respi- } \\
\text { rable }\end{array}$ & $\begin{array}{l}\text { Nonrespi- } \\
\text { rable }\end{array}$ & \\
\hline $\begin{array}{l}\text { Poor } \\
\text { Medium } \\
\text { Good }\end{array}$ & $\begin{array}{r}114 \\
65 \\
75\end{array}$ & $\begin{array}{r}51 \\
17 \\
9\end{array}$ & $\begin{array}{r}20 \\
6 \\
10\end{array}$ & $\begin{array}{r}31 \\
9 \\
16\end{array}$ & $\begin{array}{r}225000 \\
91000 \\
144000\end{array}$ & $\begin{array}{l}61000 \\
22000 \\
42000\end{array}$ & $\begin{array}{l}0.34 \\
0.18 \\
0.25\end{array}$ \\
\hline
\end{tabular}

the thermal insulation in the roof, which is thus believed to be one of the sources. In mechanically ventilated rooms (supply air) MMMF in silencers or ducts could be another source.

No grouping of ceilings was possible by surface concentration of MMMF on cupboards, even if the level of significance was raised to 0.1. Actually, no statistically significant correlation between the concentrations of total airborne and total settled fibers was found. A normalization of the surface concentration with respect to number of days since last cleaning would probably have improved the correlation. This information was not available, and reliable information may prove difficult to obtain. As demonstrated previously by others (10), surface sampling was more sensitive than air sampling for detecting the presence of MMMF in the indoor environment.

The background variables affected the concentrations as expected. It is interesting to note that the only statistically significant influence on the respirable MMMF concentration was ventilation, and for the nonrespirable MMMF the only statistically significant influence was the quality of the cleaning. These findings support theoretical calculations (11) showing that, whereas even low ventilation rates are efficient in removing respirable fibers, a ventilation rate of one air change per hour has very little effect on nonrespirable fibers. Settling is more efficient in removing nonrespirable fibers from the air. 
Table 10. Data on airborne and settled fiber size fitted with a bivariate log-normal distribution. (MMMF = man-made mineral

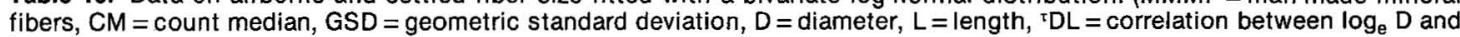
$\log _{e}$ L)

\begin{tabular}{|c|c|c|c|c|c|}
\hline Fiber type & $\begin{array}{c}\mathrm{CM}(\mathrm{D}) \\
(\mu \mathrm{m})\end{array}$ & $\mathrm{GSD}(\mathrm{D})$ & $\begin{array}{l}\mathrm{CM}(\mathrm{L}) \\
(\mu \mathrm{m})\end{array}$ & GSD(L) & ${ }^{\tau} \mathrm{DL}$ \\
\hline MMMF, settled, table & 3.7 & 1.8 & 86 & 2.9 & 0.34 \\
\hline MMMF, settled, cupboard & 3.7 & 1.8 & 76 & 2.4 & 0.33 \\
\hline non-MMMF, airborne & 1.1 & 2.3 & 11 & 2.5 & $\cdots$ \\
\hline MMMF, airborne & 2.0 & 2.0 & 28 & 2.5 & $\cdots$ \\
\hline $\begin{array}{l}\text { MMMF, airborne, calculated } \\
\text { from settled }\end{array}$ & 1.9 & 1.8 & 45 & 2.6 & 0.34 \\
\hline
\end{tabular}

Size distributions of MMMF can be described by the bivariate log-normal distribution (12). The parameters characterizing the distribution have been calculated from the pooled and grouped data according to a procedure given in reference 13 . The results, including data from two other studies to which the authors had access, are shown in table 10 . Notice that optical microscopy was used for the airborne fibers and thus the length $(5 \mu \mathrm{m})$ and diameter $(0.2 \mu \mathrm{m})$ were truncated (14). Since, in our study, the size of settled fibers was determined with a digitizer, more accurate data are available for these fibers.

The number of days since the last cleaning would not affect the size distribution of the settled fibers. If it is assumed that there is no other size-selective redistribution of settled fibers, one can calculate the size distribution on the cupboard as the size distribution in the air, weighted by the settling speed, or vice versa. By using the theoretical expression given in reference 15 , we calculated the distribution for the airborne MMMF given in table 10 from the size distribution of the settled fibers. There was very good agreement with the measured size distribution.

The number of non-MMMF was orders of magnitude greater than that of MMMF and correlated strongly with the total dust concentration. Therefore, the mass concentration of non-MMMF was estimated. This was done in the following way: the average volume of a fiber in each size class was calculated under the assumption that the fibers follow the size distribution given in table 10 . The value was not very dependent on the actual size distribution. Each nonMMMF fiber was then given this volume. Subsequently, the total volume of all fibers was correlated with the total dust concentration determined in the same room. Assuming an average density of $1 \mathrm{~g} / \mathrm{cm}^{3}$, we found that the non-MMMF fibers constituted $15-$ $20 \%$ of the weight of the total dust.

This study shows that it is possible to maintain MMMF concentrations below about 200 respirable fibers $/ \mathrm{m}^{3}$. Such concentrations present a very low risk, if any, to the general population (1). It can be concluded that mechanical ventilation, in combination with good and frequent cleaning, can be used to control the general dust level in room air.

\section{References}

1. International Programme on Chemical Safety. Manmade mineral fibers. Geneva: World Health Organization, 1988. (Environmental health criteria; no 77).

2. Schneider T. Man-made mineral fibers and other fibers in the air and in settled dust. Environ Int 1986;12:61-5.

3. Rindel A, Bach E, Breum NO, Hugod C, Schneider T. Correlating health effect with indoor air quality in kindergartens. Int Arch Occup Health 1987;59:363-73.

4. Skov P, Valbjørn O. The "sick" building syndrome in the office environment: the Danish town hall study. Environ Int 1987;13:339-49.

5. Christensen G, Knudsen FE, Nielsen PA, Lundqvist GR, Schneider T. Måling af mineralfiberafgivelse fra loftplader [Measurement of mineral fiber release from ceiling boards]. Copenhagen: Byggeindustrien, 1988: $16-20$.

6. Nielsen O. Man-made mineral fibers in the indoor climate caused by ceilings of man-made mineral wool. In: Seifert B, Esdorn H, Fisher M, Rüden H, Wegner $\mathrm{J}$, ed. Indoor air '87: Proceedings of the 4th international conference on indoor air quality and climate; vol 1. Berlin: Institute for Water, Soil and Air Hygiene, 1987:580-3.

7. Nielsen $O$, Andersen NE, Bredsdorff $P$, Linde $P$, Schneider T. Måling af mineraluldsfibre $i$ indeklimaet [Measurement of mineralwool fibers in the indoor climate]. Hørsholm (Denmark): The Danish Building Research Institute, 1989. (SBI report 201).

8. Duncan DB. A significance test for differences between ranked treatments in an analysis of variance. Va J Sci 1951;2:171-89.

9. SAS Institute Inc. SAS ${ }^{\circledR}$ procedures guide for personal computers. Version 5 Edition. Cary, NC: SAS Institute, 1985.

10. National Institute for Occupational Safety and Health. Health hazard evaluation report. Cincinnati, $\mathrm{OH}$ : Department of Health and Human Services, National Institute for Occupational Safety and Health, 1982. (HETA 81-053-1037.)

11. Schneider T, Lundqvist GR. Man-made mineral fibers in the indoor, non industrial environment. Build Environ 1986;21:129-33.

12. Holst E, Schneider T. Fiber size characterization and size analysis using general and bivariate log-normal distributions. J Aerosol Sci 1985:16:407-14.

13. Cheng YS. Bivariate log-normal distribution for characterizing asbestos fiber aerosols. Aerosol Sci Technol 1986; 5:359-68.

14. Rooker SJ, Vaughan NP, Le Guen JM. On the visibility of fibers by phase contrast microscopy. Am Ind Hyg Assoc J 1982;43:505-15.

15. Schneider T. Mass concentration of airborne man-made mineral fibres. Ann Occup Hyg 1987;31:211-7.

Received for publication: 21 December 1989 